\title{
Prediction of Soil Stresses Beneath a Rigid Wheel
}

\author{
R. L. Raper;* C. E. Johnson, $\dagger$ A. C. Bailey;* E. C. Burt;* W. A. Block $\dagger$ \\ *USDA, ARS, National Soil Dynamics Laboratory, Auburn, AL 36831, U.S.A. †Agricultural Engineering Department, Alabama \\ Agricultural Experiment Station, Auburn University, AL 36849 U.S.A.
}

(Received 27 May 1993; accepted in revised form 27 January 1995)

A finite element modeling technique is being developed as a management tool that can be used to predict and avoid excessive soil compaction. Values of normal stress between a rigid wheel and the soil were obtained using an instrumented bar across the width of the wheel. These values were used to apply loads to the finite element model. A non-linear stress-strain relationship was used that shows that soil compaction is a function of both normal and shearing stress. The linear-elastic parameters, Young's Modulus and Poisson's ratio, are updated at small increments of load to follow the non-linear stress-strain relationship closely. Values of octahedral normal (mean normal) and major principal stress are predicted accurately in some situations but not at the high load condition in an initially uniformly loose soil profile.

\section{Introduction}

Soil compaction continues to cause a decrease in crop yields in the U.S.A. and around the world. Research throughout much of the developed world is now devoted to predicting and avoiding the effects of soil compaction. Soil compaction not only affects crop yields, 'but also increases energy usage to till compacted layers. Soil compaction can also affect water quality when infiltration is reduced and soil erosion is thereby increased.

A model that would allow producers to manage the effects of soil compaction could be most helpful if it accurately predicted situations where excessive soil compaction could occur. Such a model is the object of research at the National Soil Dynamics Laboratory (NSDL) and Agricultural Engineering Department at Auburn University (AU), Auburn, AL, USA.

Soil compaction created by a rigid wheel was chosen to be modeled because the normal and tangential stresses applied at the surface of the wheel are not

Alabama Agricultural Experiment Station Journal No. 2-923224. Presented at Ag Eng 92, Uppsala, Sweden, June 1-4, 1992. difficult to measure and the rigid geometry permits the determination of the direction of these stresses. A true three-dimensional device (such as an agricultural tractor tyre) is much more difficult to model because the th direction of the stresses at the soil interface are generally unknown and difficult to measure.

The objectives of this research effort were to: (i) create a finite element model that predicts soil stresses beneath a rigid wheel, (ii) develop a method of applying normal stresses measured in an experimental apparatus to the finite element model, and (iii) verify these predictions against values measured in an experiment in a soil bin.

\begin{tabular}{|cl|}
\hline & \multicolumn{1}{c|}{ Notation } \\
$\epsilon_{\mathrm{v}}$ & Volumetric strain (change in \\
& volume/original volume) \\
$\sigma_{\text {hyd }}$ & Hydrostatic stress, $\mathrm{kPa}$ \\
$A$ & Compactibility coefficient \\
$B$ & Compactibility coefficient, $1 / \mathrm{kPa}$ \\
$C$ & Compactibility coefficient, $1 / \mathrm{kPa}$ \\
$\bar{\epsilon}_{\mathrm{v}}$ & Natural volumetric strain, \\
& ln (volume/original volume) \\
$\sigma_{\text {oct }}$ & Normal stress on the octahedral plane \\
& kPa \\
$\tau_{\text {oct }}$ & Shear stress on the octahedral plane \\
& kPa \\
$D$ & Compactibility coefficient \\
$\sigma_{1}$ & Major principal stress, $\mathrm{kPa}$ \\
$\sigma_{2}$ & Intermediate principal stress, $\mathrm{kPa}$ \\
$\sigma_{3}$ & Minor principal stress, $\mathrm{kPa}$ \\
$\tau_{\text {oct }}$ & Ultimate shearing stress at maximum \\
& density, kPa \\
$K$ & Coefficient representing soil plastic flow \\
& yield \\
$E$ & Young's modulus, kPa \\
$v$ & Poisson's ratio \\
$\Delta \epsilon_{1}$ & Incremental axial strain \\
$\Delta \epsilon_{\mathrm{v}}$ & Incremental volumetric strain \\
$\tau_{\text {max }}$ & Maximum shear stress, $\mathrm{kPa}$ \\
&
\end{tabular}


$\bar{\epsilon}_{\text {v-ss }} \quad$ Natural volumetric strain occurring after shear stress is initiated

$\bar{\epsilon}_{1} \quad$ Maximum natural principal strain

$\bar{\epsilon}_{3} \quad$ Minimum natural principal strain

$\bar{\gamma}_{\max } \quad$ Maximum natural shearing strain defined as $\left(\bar{\epsilon}_{1}-\bar{\epsilon}_{3}\right)$

$I \quad$ Intercept of $\bar{\gamma}_{\max } / \bar{\epsilon}_{\mathrm{v}-\mathrm{ss}}$ when $\tau_{\max } / \sigma_{1}=0$

$K^{\prime} \quad$ Coefficient

$h$ Coefficient

\section{Model development}

Finite element analysis has been used during the past several decades to analyse soil-machine interactions and to predict the forces that are generated when a tool moves through the soil. ${ }^{1,2}$ Finite element models have also been used to predict the effect the tool (or vehicle) would have on the soil (i.e., soil compaction) ${ }^{3-5}$ Although significant strides have been made, much remains to be done to model soil compaction beneath a tractive device effectively.

\subsection{Stress-strain development}

A complete stress-strain relationship for agricultural soil must be developed before soil compaction or soil stresses can be predicted from loads applied to the surface. Several soil compaction or stress-strain relationships have been proposed for agricultural soil. One approach that has been taken at the NSDL and AU has been to use data obtained from triaxial tests to model the volumetric strain as a function of hydrostatic stress. ${ }^{6}$

$$
\epsilon_{\mathrm{v}}=\left(A+B_{\text {hyd }}\right)\left(1-\mathrm{e}^{-C \sigma_{\text {hyd }}}\right) .
$$

where $\epsilon_{\mathrm{v}}$ is volumetric strain, (change in volume/original volume); $\sigma_{\text {hyd }}$ is hydrostatic stress; $A$, $B$, and $C$ are compactibility coefficients established by fitting data to the equation.

This soil compaction model gave reasonảbly accurate predictions, but included the assumption of a hydrostatic stress state. This stress state exists only when the three principal stresses are equal. The situation rarely exists in nature, but the model gave reasonable results and provided a valuable starting point.

Bailey and Johnson' proceeded to develop a more complete model based on stresses found on the octahedral plane.*

$$
\bar{\epsilon}_{\mathrm{v}}=\left(A+B \sigma_{\text {oct }}\right)\left(1-\mathrm{e}^{-C \sigma_{\text {oct }}}\right)+D\left(\frac{\tau_{\text {oct }}}{\sigma_{\text {oct }}}\right)
$$

where $\bar{\epsilon}_{\mathrm{v}}$ is natural volumetric strain, ln (volume/original volume); $\sigma_{\text {oct }}$ is the normal stress on the octahedral plane; $\tau_{\text {oct }}$ is the shear stress on the octahedral plane; $D$ is an additional compactibility coefficient. These stresses are defined according to the following equations.

$$
\begin{aligned}
& \sigma_{\text {oct }}=\left(\sigma_{1}+\sigma_{2}+\sigma_{3}\right) / 3 \\
& \tau_{\text {oct }}=\sqrt{\left(\sigma_{1}-\sigma_{2}\right)^{2}+\left(\sigma_{2}-\sigma_{3}\right)^{2}+\left(\sigma_{3}-\sigma_{1}\right)^{2}} / 3
\end{aligned}
$$

where $\sigma_{1}, \sigma_{2}, \sigma_{3}$ are the principal stresses.

Limitations were placed on the octahedral shearing stress in Eqn (2) to indicate maximum density at plastic flow.

$$
\tau_{\text {oct }}=K \sigma_{\text {oct }}
$$

where $\tau_{\text {octy }}$ is ultimate shearing stress at maximum density and $K$ is a coefficient representing soil plastic flow yield. The above models were based on triaxial data obtained up to maximum applied stress values of $500 \mathrm{kPa}$.

\subsection{Finite element model development}

The incorporation of these models, which predict stress at a point, into a program to predict stress distribution is of similar importance to developing an adequate stress-strain relationship. The finite element method allows input loads, stress-strain relationships and any resulting deformations for an individual element to be linked mathematically to all other elements in the model. This, approach allows predictions of stresses and strains to be obtained throughout the entire model. The finite element program that has been developed for soil compaction/soil stress modeling consists of a materially non-linear, iterative approach. ${ }^{9}$ The stress-strain relationship is assumed to be linear-elastic over small increments of strain. The strains and resulting stresses are summed over each iterative cycle.

To use the linear-elastic approach, values of a tangential Young's modulus $(E)$ and Poisson's ratio (v) are needed. These values are continually updated to reflect changing values of $\boldsymbol{E}$ and $v$ with increasing stress levels. A Newton-Raphson iterative technique was used to iterate on each incremental load step until each degree of freedom converged. ${ }^{10}$ 


\subsubsection{Poisson's ratio}

An equation obtained from research reported by Duncan and Chang ${ }^{11}$ was used to obtain values of Poisson's ratio from two incremental values of volumetric and axial strain.

$$
v=\frac{\Delta \epsilon_{1}-\Delta \epsilon_{\mathrm{v}}}{2 \Delta \epsilon_{1}}
$$

where $\Delta \epsilon_{1}$ is incremental axial strain; $\Delta \epsilon_{\mathrm{v}}$ is incremental volumetric strain.

The finite element model is first run with values of the linear-elastic parameters at zero stress levels. The predicted stresses by the finite element method are used to calculate a value of volumetric strain by using Eqn (2). Two values of this parameter are necessary because Eqn (6) uses incremental strain. The mea" normal stress from the finite element model was then increased by a" infinitesimal amount of $1 \%$ to obtain another unique value of volumetric strain.

The determination of values of incremental axial strain $\left(\mathrm{DI}_{1}\right)$ was more complicated. Recent research conducted by Johnson and Bailey ${ }^{12}$ using a triaxial apparatus suggests that a value of shearing strain can be calculated according to the following relationship.

$$
\bar{\gamma}_{\max } / \bar{\epsilon}_{\mathrm{v}-\mathrm{ss}}=I-\ln \left[1-\left(\tau_{\max } / K^{\prime} \sigma_{1}\right)\right] / h
$$

where $I$ is the intercept of $\bar{\gamma}_{\max } / \bar{\epsilon}_{\mathrm{v} \text {-ss }}$ when $\tau_{\max } / \sigma_{1}=0$; $\tau_{\max }$ is maximum shear stress; $\sigma_{1}$ is major principal stress; $\bar{\gamma}_{\max }$ is maximum natural shearing strain defined as $\left(\bar{\epsilon}_{1}-\bar{\epsilon}_{3}\right)$ where $\bar{\epsilon}_{1}$ and $\bar{\epsilon}_{3}$ are maximum and minimum natural principal strains; $\bar{\epsilon}_{\mathrm{v} \text {-ss }}$ is natural volumetric strain occurring after shear stress is initiated; $K^{\prime}$ and $h$ are coefficients.

Because of the axisymmetric geometry of the triaxial apparatus $\left(\bar{\epsilon}_{2}=\bar{\epsilon}_{3}\right)$, a value of natural axial strain can be obtained from the relation $\bar{\epsilon}_{\mathrm{v}-\mathrm{ss}}=$ $\bar{\epsilon}_{1}+2 \bar{\epsilon}_{3}$. A value of Poisson's ratio is then calculated from Eqn (6).

\subsubsection{Young's modulus}

The principal stresses predicted from the finite element model were used to calculate a value of natural volumetric strain from Eqn (2). This value of strain was then used with an iterative solution scheme to determine a similar value of hydrostatic stress from Eqn (1) that gave the same natural volumetric strain. A value of Young's modulus was then determined from the know" quantities, including the predicted value of Poisson's ratio. ${ }^{13}$

$$
E=\frac{-3(1-2 v)}{\epsilon_{\mathrm{v}}} \sigma_{\mathrm{hyd}}
$$

\section{Experimental procedure}

A" experiment was performed in the indoor soil bins at the NSDL that used a rigid wheel as the loading device. The rigid wheel had a diameter of $137 \cdot 2 \mathrm{~cm}$ and a width of $30 \cdot 5 \mathrm{~cm}$ (Fig. 1). The experiment consisted of operating the rigid wheel at two dynamic loads in a Norfolk sandy loam soil which was prepared with two soil conditions. The soil conditions were a uniformly loose soil and a loose surface overlying a hard pa". The soil conditions and soil constants are given in Table 1 . The two dynamic loads were $11 \cdot 6 \mathrm{kN}$ and $5 \bullet 8 \mathrm{kN}$. All tests were run with a constant level of $10 \%$ slip. Three replications were run for each treatment.

A normal stress bar was mounted on the rigid wheel to measure the applied normal stress (Fig. I). As the normal stress bar came into contact with the soil, values of normal stress between the wheel and the soil were measured at approximately every $1.5^{\circ}$ of wheel rotation. The vertical component of these normal stress values were used to provide load for the finite element model.

Stress state transducers ${ }^{14}$ (SST's) were placed in the soil along the centerline of the wheel either at a depth

of $30 \mathrm{~cm}$ in the loose soil or on the hard pan in this soil condition. These transducers measure the soil stresses in six directions that have the unique relationship of allowing the complete stress state at a point to be calculated. These stresses were measured as the rigid wheel passed over the SST. Values of octahedral normal stress, octahedral shearing stress and major principal stresses were then calculated.

A plane strain finite element model was used to investigate the stresses predicted throughout the soil profile. This model assumed the wheel to be of infinite

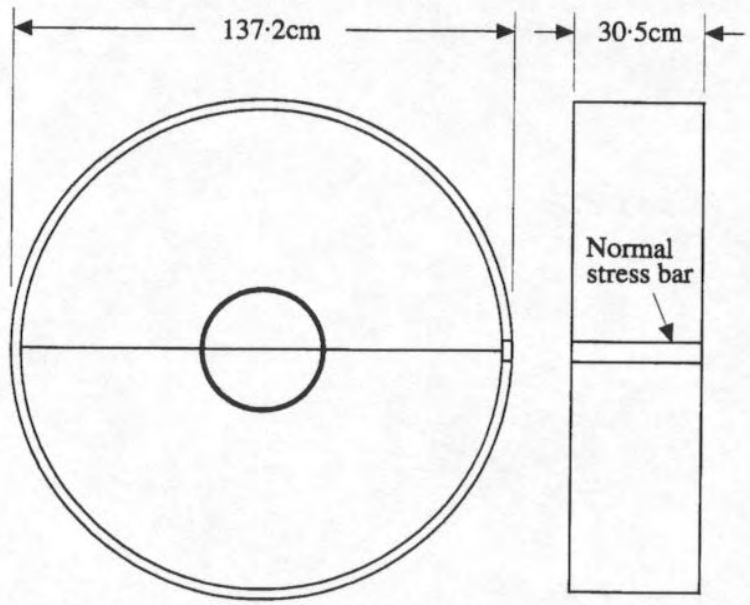

Fig. 1. Rigid wheel used for the experiment in the soil bins at the NSDL 
Table 1

Current soil condition parameters and statistically fitted coefficients for Norfolk sandy loam

\begin{tabular}{lc}
\hline Sand/silt/clay ratio & $0 \cdot 72 / 0 \cdot 17 / 0 \cdot 11$ \\
Bulk density at $15 \mathrm{~cm}$ depth & $1 \cdot 38 \mathrm{Mg} / \mathrm{m}^{3}$ \\
Bulk density at $30 \mathrm{~cm}$ depth & $1 \cdot 42 \mathrm{Mg} / \mathrm{m}^{3}$ \\
Moisture content at $15 \mathrm{~cm}$ depth & $9 \cdot 02 \%$ \\
Moisture content at $30 \mathrm{~cm}$ depth & $8 \cdot 79 \%$ \\
Coefficient A Eqns (1) and (2) & $-0 \cdot 241$ \\
Coefficient B Eqns (1) and (2) & $-179 \times 10^{-6} / \mathrm{kPa}$ \\
Coefficient C Eqns (1) and (2) & $12 \cdot 6 \times 10^{-3} / \mathrm{kPa}$ \\
Coefficient D Eqn (2) & $-0 \cdot 1122$ \\
Coefficient K Eqn (3) & $0 \cdot 736$ \\
Coefficient K' Eqn (7) & $0 \cdot 762$ \\
Coefficient h Eqn (7) & 1.807 \\
Initial Young's Modulus & $326 \cdot 2 \mathrm{kPa}$ \\
Initial Poisson's Ratio & 0.0 \\
\hline
\end{tabular}

width. This two-dimensional assumption is broad but the predicted stresses should not differ greatly from stresses measured beneath the center of the rigid wheel. The normal stresses measured using the normal stress bar were used to load the finite element model. Only the vertical stress component of the normal stress was used to load the soil in a static manner. Dynamic effects and tangential stresses are not considered in this analysis.

The mesh that was designed to investigate this plane strain problem is shown in Fig. 2 along with a deformed grid that is overlaid. Only one-half of the

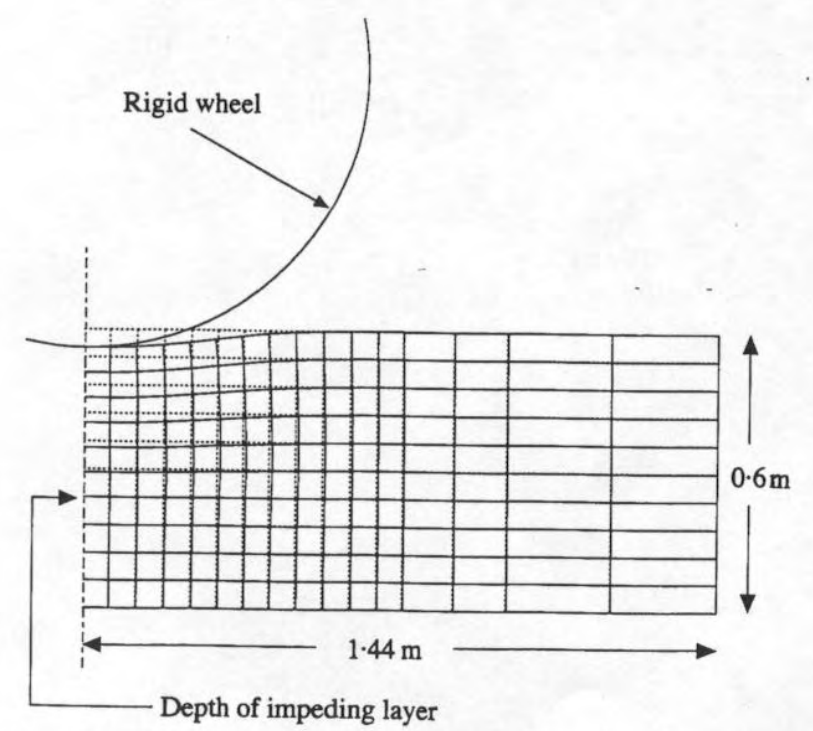

Fig. 2. Original finite element mesh and final displaced mesh showing location of impeding layer in Norfolk sandy loam soil when loosely tilled. Only one-half of the soil was modelled beneath the rigid wheel because of symmetry. ...., original mesh; - deformed mesh rigid wheel was modelled because of assumed symmetry. Twenty load steps were used to increment the loads using the finite element model. This value was determined as sufficient after several trial runs. A maximum number of five iterations was used to determine agreement in degree of freedom displacements to the nearest $0 \bullet 001 \mathrm{~m}$. Convergence was always achieved in three or fewer iterations.

Penetrometer measurements that were obtained at the conclusion of the experiment showed that a root-restricting layer was present in the hard pan treatment at a depth of $36 \mathrm{~cm}$. In the uniformly loose soil treatments, this layer was found at $48 \mathrm{~cm}$. In the finite element analysis, the vertical displacements of nodes found at these corresponding depths were fixed to not allow any further compaction beneath these depths.

\section{Results and discussion}

Vertical stress values obtained from the normal stress bar as the rigid wheel enters the soil are given in

Table 2

Vertical stress measured by the normal stress bar on the rigid wheel at the positions indicated measured from the center of the wheel

\begin{tabular}{lrrrrrrrr}
\hline \multicolumn{10}{c}{ Distance from centre of wheel, $m$} \\
\hline & $0 \cdot 0$ & $0 \cdot 06$ & $0 \cdot 12$ & $0 \cdot 18$ & $0 \cdot 24$ & $0 \cdot 30$ & $0 \cdot 36$ & $0 \cdot 42$ \\
\hline Test code $\dagger$ & \multicolumn{10}{c}{ Vertical stress measured by normal stress bar, $k P a$} \\
\hline 111121 & 35 & 74 & 72 & 56 & 39 & 20 & 1 & 0 \\
111122 & 28 & 54 & 60 & 57 & 46 & 40 & 26 & 0 \\
111123 & 25 & 60 & 65 & 65 & 55 & 44 & 9 & 0 \\
111141 & 25 & 95 & 94 & 81 & 65 & 48 & 32 & 6 \\
111142 & 76 & 99 & 97 & 88 & 72 & 52 & 33 & 1 \\
111143 & 30 & 99 & 102 & 93 & 74 & 53 & 36 & 15 \\
121121 & 6 & 55 & 57 & 51 & 41 & 34 & 7 & 0 \\
121122 & 30 & 70 & 64 & 54 & 41 & 25 & 6 & 0 \\
121123 & 48 & 74 & 60 & 48 & 34 & 20 & 0 & 0 \\
121141 & 59 & 112 & 108 & 91 & 70 & 45 & 23 & 0 \\
121142 & 94 & 118 & 110 & 92 & 70 & 42 & 13 & 0 \\
121143 & 105 & 110 & 97 & 80 & 61 & 40 & 10 & 0 \\
\hline
\end{tabular}

$\dagger \quad$ First digit $=1$, Norfolk sandy loam soil

Second digit $=1$, Loose soil condition $=2$, Hard pan soil condition

Third digit $=1$, Use of SST's

Fourth digit $=1,10 \%$ slip

Fifth digit $=2,5.6 \mathrm{kN}$ load $=4,11.2 \mathrm{kN}$ load

Sixth digit $=1,2$, or 3 replication 


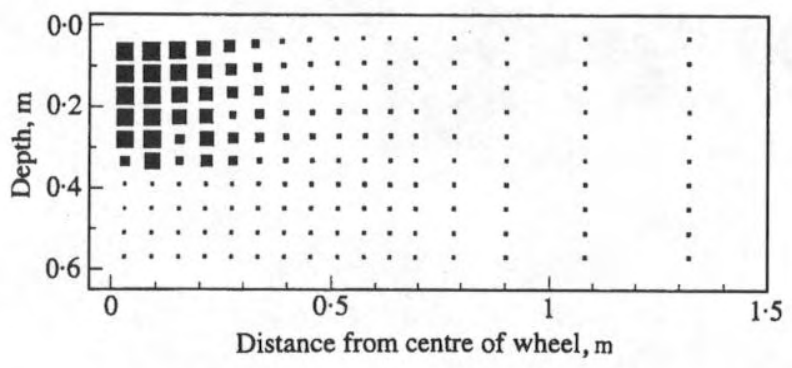

Fig. 3. Predicted major principal stress distribution for the second replication of the test in the Norfolk sandy loam soil, hard pan condition, at $10 \%$ slip, with a $11.2 \mathrm{kN}$ load. The size of the marker indicates the magnitude of the major principal stress $(\mathrm{kPa})$ according to the key below.

$$
\text { ., } 100 ; . \mathbf{m} \text {; ., 50; ., 25; ., } 0
$$

Table 2. As can be seen from the table, the data are quite variable. The assumption that was made to model only half of the rigid wheel may be questionable because of the decrease of vertical stress observed under the center of the wheel.

The major principal stress data for test 121142 is given in Fig. 3. As would be expected, the stresses are greatest near the point of load application and decrease as depth increases. The predicted volumetric strain distribution, also for test 121142, is given in Fig. 4. Note that the location of maximum volumetric strain may or may not coincide with the maximum major principal stress. This is owing to the stressstrain relationship used which depends both on octahedral normal and shearing stress.

A comparison between the measured values obtained from the SST's and those predicted by the finite element model is shown in Fig. 5. Generally the finite element model predicts within an acceptable $95 \%$ confidence interval of the measured values. This was not true, however, for the $11 \cdot 2 \mathrm{kN}$ load in the loose soil condition and only marginally so for the $11 \cdot 2 \mathrm{kN}$

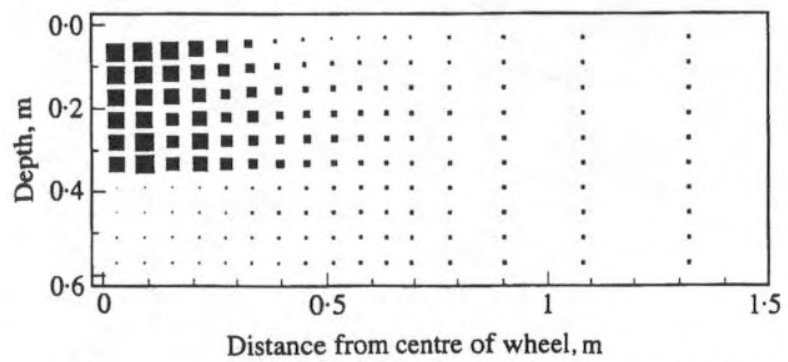

Fig. 4. Predicted volumetric strain distribution for the second replication of the test in the Norfolk sandy loam soil, hard pan condition, at $10 \%$ slip, with a $11 \cdot 2 \mathrm{kN}$ load. The size of the marker indicates the magnitude of the volumetric strain according to the key below.

= $0.1 ;$. $0.08 ;., 0.06 ; .0 .04 ; .0 .02 ; .0$
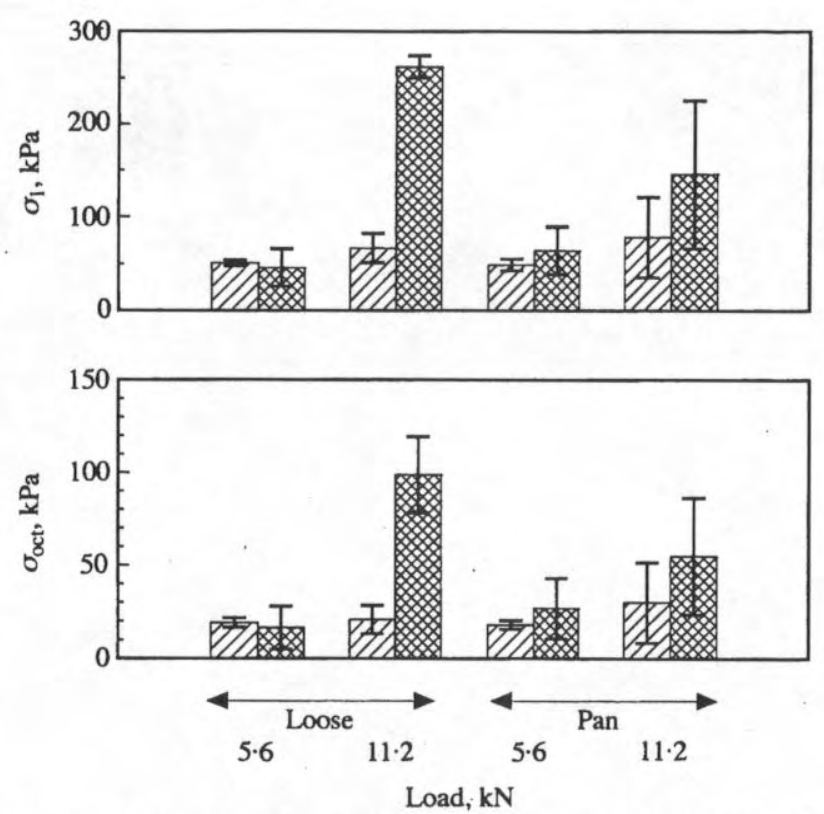

Fig. 5. Finite element predicted stress values compared with SST measured values at the centre of the rigid wheel at a depth of $30 \mathrm{~cm}$ along with $95 \%$ confidence intervals for the Norfolk sandy loam soil. $\sigma_{1}$, major principal stress; $\sigma_{o c t}$, normal stress on octahedral plane.

, finite element prediction; measured

load in the hardpan soil condition. The measured stress seems to be excessive and not effectively modeled. One possible reason for this error is that the method of modeling failed to account for the driving tractive force of the wheel and used as inputs only the vertical normal force. The data itself may be questionable because the stress values usually rise when a hard pan is present. However, from Fig. 5, it can easily be seen that the measured stress values decreased when a hard pan was present.

\section{Conclusions}

1. A finite element model has been constructed to model a rigid wheel in a plane strain manner.

2. The stresses applied by the rigid wheel were measured by a normal stress bar and were used to apply loads to the soil surface in the finite element model.

3. At low dynamic loads, both for the hard pan and for the uniformly loose soil conditions, predictions were within the $95 \%$ confidence intervals of measured values. At high dynamic loads, the finite element predictions were not as accurate. The model grossly underpredicted stresses for the high dynamic load in the uniformly loose soil condition. In this case, the predictions were about $25 \%$ of the measured values. 


\section{References}

${ }^{1}$ Chi L; Kushwaha R L A non-linear 3-D finite element analysis of soil failure with tillage tools. Journal of Terramechanics 1991,27(4): 343-366.

${ }^{2}$ Yong R N; Hanna A W Finite element analysis of plane soil cutting. Journal of Terramechanics 1977, 14(3): 103-125

${ }^{3}$ Perumpral J V; Liljedahl J B; Perloff $\mathbf{W} \mathbf{H}$ The finite element method for predicting stress distribution and soil compaction under tractive devices. Transactions of ASAE 1971,14(6): 1184-1188

4 Pollock Jr D; Perumpral J V; Kuppusamy T Finite element analysis of multipass effects of vehicles on soil compaction. Transactions of ASAE 1985,29(1): 45-50

5 Yong R N; Fattah E A; Booninsuk P Analysis and prediction of tyre-soil interaction and performance using finite elements. Journal of Terramechanics 1978, 15(1): 43-63

${ }^{6}$ Bailey A C; Johnson C E; Schafer R L Hydrostatic compaction of agricultural soils. Transactions of ASAE 1984,27(4): 952-955
${ }^{7}$ Bailey A C; Johnson E C A soil compaction model for cylindrical stress states. Transactions of ASAE 1989, 32(3): 822-825

${ }^{8}$ Hettiaratchi D R P; O'Callaghan J R Mechanical behavior of agricultural soils. Journal of Agricultural Engineering Research 1980,25(3): 239-259

${ }^{9}$ Raper R L: Erbach D C Prediction of soil stresses using finite element analysis. Transactions of ASAE 1990; 33(3): 725-730

${ }^{10}$ Cook R D Concepts and applications of finite element analysis. John Wiley \& Sons, Inc., 1981, pp. 354-357

${ }^{11}$ Duncan J M; Chang C Y Nonlinear analysis of stress and strain in soils. Journal of Soil Mechanics and Foundations Division, Proceedings of American Society of Civil Engineers 1970,96(5): 1629-1653

12 Johnson C E; Bailey A C A shearing strain model for cylindrical stress states. ASAE St. Joseph, MI, 1990. ASAE Paper 90-1085

13 Popov E P Mechanics of materials. Prentice-Hall, Inc. 1976, p. 265

${ }^{14}$ Nichols T A; Bailey A C; Johnson C E; Grisso R D A stress state transducer for soil. Transactions of ASAE 1987, 30(5): 1237-1241 